\title{
Pancreatic endotherapy in management of rare case of pancreatico-pericardial fistula post chronic pancreatitis: A case report
}

\author{
Vikas Pandey, Kaivan Shah, Nilesh Pandav, Meghraj Ingle, \\ Aniruddha Phadke, Prabha Sawant
}

\begin{abstract}
Introduction: Acute or chronic pancreatitis has been known to be associated with complications like Pseudocyst, pancreatic necrosis,splenic vein thrombosis, pancreatic ascites and pleural effusion. Rarelydowefind presentation of patient with cardiac tamponade and gross pericardial effusion due to pancreaticopericardial fistula. Case Report: We report a case of a 38-yearold male presented with chest tightness, abdominal fullness and dull aching abdominal pain. Chest $X$-ray was suggestive of pericardial effusion which recurred immediately. Contrastenhanced computed tomography (CECT) scan of abdomen revealed dilated MPD (main pancreatic duct), pseudocyst in head region extending up to epigastrium and communicating with collection under dome of diagphragm and with pericardial effusion. Endoscopic retrograde cholangiopancreaticography was performed, with pancreaticogram
\end{abstract}

Vikas Pandey ${ }^{1}$, Kaivan Shah ${ }^{1}$, Nilesh Pandav ${ }^{1}$, Meghraj Ingle $^{2}$, Aniruddha Phadke ${ }^{3}$, Prabha Sawant ${ }^{4}$

Affiliations: 'Senior Resident, LTMMC \& LTMGH, Sion, Mumbai 400022; ' 2 Assistant Professor, Department of Gastroenterology, LTMMC \& LTMGH, Sion, Mumbai 400022; ${ }^{3}$ Associate Professor, LTMMC \& LTMGH, Sion, Mumbai 400022; ${ }^{4}$ Professor and Head of the Department, LTMMC \& LTMGH, Sion, Mumbai 400022.

Corresponding Author: Vikas Pandey, Senior resident, Department of Gastroenterology, Lokmanya Tilak Medical College \& Sion Hospital Mumbai -22; Email: reenaupadhyay66@gmail.com

Received: 10 May 2015

Accepted: 12 June 2015

Published: 11 July 2015 revealed pancreatic dye leaking into posterior mediastinum and communicating -pericardial cavity thus forming an effusion. Pancreatic duct stenting with $7 \mathrm{Fr}$ stent was done and patient recovered uneventfully. Conclusion: Pancreaticopericardial fistula presenting with cardiac tamponade is a rare presentation of alcoholic chronic pancreatitis. Conventionally, surgical options in form of lateral pancreatojejunostomy is considered treatment of choice. Our case has been managed successfully by ERCP and pancreatic duct stenting which could be an effective option thus avoiding surgery.

Keywords: Endotherapy, Fistula, Pancreatico-pericardial, Pancreatitis

\section{How to cite this article}

Pandey V, Shah K, Pandav N, Ingle M, Phadke A, Sawant P. Pancreatic endotherapy in management of rare case of pancreatico-pericardial fistula post chronic pancreatitis: A case report. Int $J$ Hepatobiliary Pancreat Dis 2015;5:70-73.

Article ID: 100037IJHPDVP2015

$* * * * * * * * *$

doi:10.5348/ijhpd-2015-37-CR-12

\section{INTRODUCTION}

Acute or chronic pancreatitis has been known to be associated with complications like pseudocyst, 
pancreatic necrosis, splenic vein thrombosis, pancreatic ascites and pleural effusion. Cardiac tamponade is a rare complication of chronic pancreatitis and presentation with this complaint is extremely rare.

\section{CASE REPORT}

A 38-year-old male presented to the emergency department with history of severe breathlessness, chest pain and abdominal pain since two days. His symptoms had gradually progressed over one month with dyspnea progressing from NYHA (New York heart association classification) class 1 to class 4 . He also complained of chest tightness, abdominal fullness and dull aching abdominal pain. He was admitted in MICU (medical intensive care unit) and was found to be having hypotension, tachycardia, pallor, tachypnea. Physical examination revealed muffled heart sounds, elevated JVP, normal respiratory examination. Abdominal examination revealed epigastric tenderness and shifting dullness. His hemoglobin was $9.8 \mathrm{~g} / \mathrm{dl}$, TLC 15,000, serum creatinine $0.7 \mathrm{mg} / \mathrm{dl}$, BUN $8 \mathrm{mg} / \mathrm{dl}$, random sugar $84 \mathrm{mg} / \mathrm{dl}$, total protein $5.6 \mathrm{~g} / \mathrm{dl}$ and serum albumin 2.9 $\mathrm{g} / \mathrm{dl}$ and normal serum electrolytes. Serum bilirubin, SGPT, SGOT, prothrombin time with INR were normal. Bed side X-ray chest revealed water bottle shape heart which was suggestive of pericardial effusion. Urgent pericardiocentesis was performed and $1000 \mathrm{ml}$ fluid was removed. Next day patient again complained of dyspnea, computed tomography scan of thorax revealed gross pericardial effusion with collapse of right atrium and right ventricle. Patient was re-trapped and percutaneous drain was kept. Ultrasound scan of abdomen showed mild to moderate ascites, heterogeneous pancreas with $2 \times 2 \mathrm{~cm}$ pseudocyst and prominent pancreatic duct. Gastromedicine opinion was sought. His past history revealed multiple episodes of severe abdominal pain for which he was admitted twice, and managed conservatively. Patient was consuming 1-2 quarters of country liquor/ day. S amylase, ascitic and pericardial fluid amylase levels and CECT scan of abdomen was advised. Ascitic fluid analysis revealed low SAAG (serum albumin ascites gradient) with high protein, and ascitic and pericardial fluid amylase were high (2540 and 3235 IU/L). CECT scan of abdomen revealed dilated MPD (main pancreatic duct), pseudocyst in head region extending up to epigastrium and communicating with collection under dome of diaphragm with pericardial effusion. (Figure 1A-B) ERCP was performed, pancreatogram revealed pancreatic dye leaking into posterior mediastinum and communicating with pericardial cavity thus forming an effusion. Pancreatic sphincterotomy was done and $5 \mathrm{Fr} \times 12 \mathrm{~cm}$ stent was deployed bridging the leak (Figure $2 \mathrm{~A}-\mathrm{D}$ ). Post procedure nasojejunal (NJ) was inserted, antibiotics and octreotide was continued. Post stenting patient improved with gradual disappearance of ascites and pericardial effusion with no further tapping required.
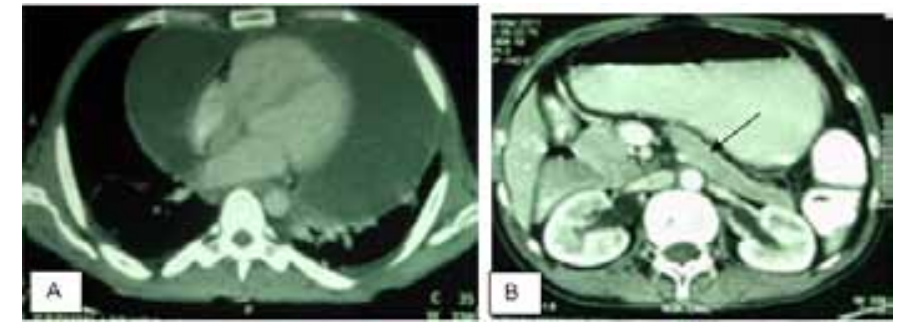

Figure 1: A Computed tomography scan showing pericardial effusion, and (B) Dilated pancreatic duct suggestive of chronic pancreatitis.
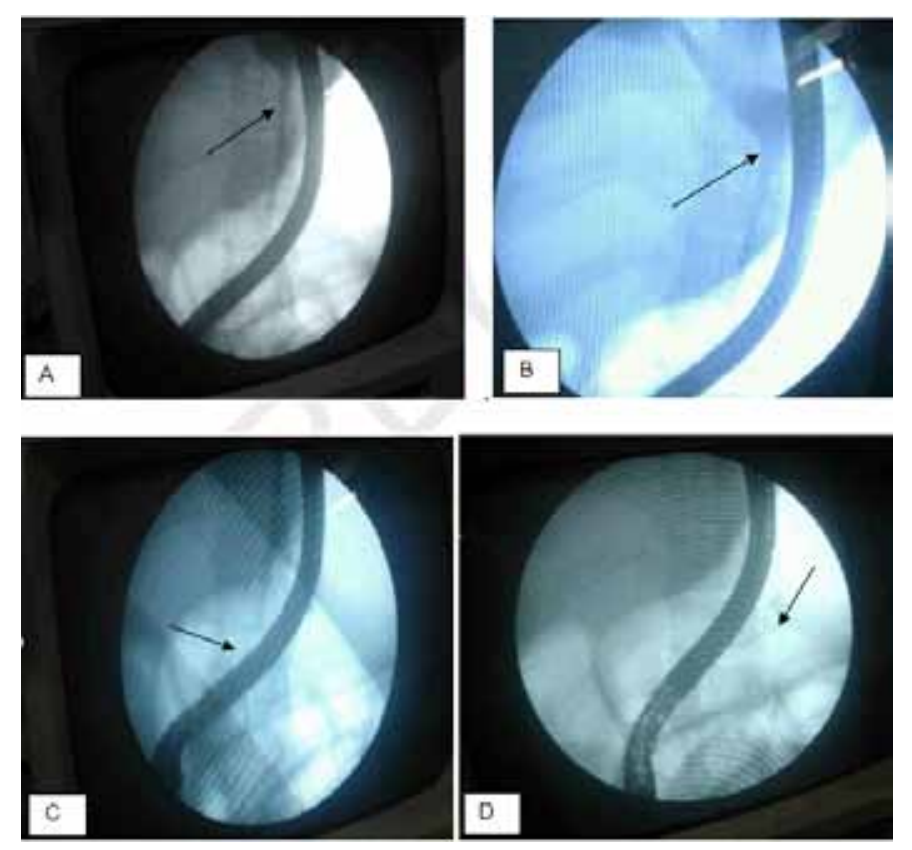

Figure 2: Upper panel (A, B) showing pancreatico-pericardial fistula during ERCP, (C) Arrow showing guidewire in the pancreatic duct, and (D) Arrow pointing towards pancreatic stent bridging the leak.

Patient was subsequently discharged and stent removed after 2months during which repeat pancreatogram was performed which showed no leak. Patient is in our follow up and is doing well.

\section{DISCUSSION}

Pancreatitis either acute or chronic is associated with various complications viz. pseudocyst (5-25\%), splenic vein thrombosis (4-5\%), splenic artery pseudoaneurysm, (5-20\%), common bile duct obstruction (8-10\%), duodenal stenosis (4-5\%) and internal and external fistulas. Pleural effusion and ascites as sequalae of post acute or chronic pancreatitis are common. Pancreatic leak into serosal cavity resulting into pleural effusion and ascites occurs in $3-5 \%$ of patients with chronic pancreatitis and $6-14 \%$ of patients with pancreatic pseudocyst [1]. Postulated mechanisms in case of chronic pancreatitis are either due to pseudocyst communication with the serosal cavity or due to duct disruption. Pancreaticopleural and 
pancreatico-pericardial fistula are considered as rare complications of chronic pancreatitis. mechanism of pericardial effusion is not clear. Earlier it was believed to be due to pancreatic enzymes induced chemical pericarditis and pleurisy. Cameron proposed hypothesis that anterior duct disruption produces effusion and ascites while posterior duct dispersion communicates retroperitoneally with posterior mediastinum to produce pericardial effusion [2]. Our patient presented with progressive dyspnea and chest pain with intermittent abdominal pain. It was only when the pericardial fluid was tapped and analyzed and found to have elevated amylase concentrations, pancreatic origin of the pericardial fluid was suspected.

Initial pericardial tapping, antibiotics, NJ feeding and octreotide followed by surgery in form of lateral pancreaticojejunostomy has been considered the appropriate protocol [3]. Another report described an adult patient who underwent an elective Roux-en-Y pancreaticojejunostomy without complication and remained symptom-free two years after surgery [4]. In our case, we have successfully managed the case with pancreatic endotherapy. To the best of our knowledge there is no published report of successful endotherapy in pancreatico-pericardial fistula. Even in recent case report pancreatico-pericardial fistula had not responded to endotherapy [5]. The long-term result of such management is not known and needs to be validated. The success of endotherapy depends on passing the guidewire across the leak, absence of tight strictures and deployment of appropriate length stent.

\section{CONCLUSION}

Pancreatico-pericardial fistula presenting with cardiac tamponade is a rare presentation of alcoholic chronic pancreatitis. Conventionally, surgical options in form of lateral pancreaticojejunostomy are considered treatment of choice. Our case has been managed successfully by ERCP (endoscopic retrograde cholangiopancreatography) and pancreatic duct stenting which could be an effective option thus avoiding surgery.

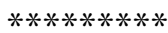

\section{Author Contributions}

Vikas Pandey - Substantial contributions to conception and design, Acquisition of data, Analysis and interpretation of data, Drafting the article, Revising it critically for important intellectual content, Final approval of the version to be published

Kaivan Shah - Analysis and interpretation of data, Revising it critically for important intellectual content, Final approval of the version to be published

Nilesh Pandav - Analysis and interpretation of data, Revising it critically for important intellectual content,
Final approval of the version to be published

Meghraj Ingle - Analysis and interpretation of data, Revising it critically for important intellectual content, Final approval of the version to be published

Aniruddha Phadke - Analysis and interpretation of data, Revising it critically for important intellectual content, Final approval of the version to be published

Prabha Sawant - Analysis and interpretation of data, Revising it critically for important intellectual content, Final approval of the version to be published

\section{Guarantor}

The corresponding author is the guarantor of submission.

\section{Conflict of Interest}

Authors declare no conflict of interest.

\section{Copyright}

(C) 2015 Vikas Pandey et al. This article is distributed under the terms of Creative Commons Attribution License which permits unrestricted use, distribution and reproduction in any medium provided the original author(s) and original publisher are properly credited. Please see the copyright policy on the journal website for more information.

\section{REFERENCES}

1. K. Prakash. Pancreatic Ascites and Pleural Effusion, Pancreatitis - Treatment and Complications, Prof. Luis Rodrigo (Ed.), (2012). Available from: http:// www.intechopen.com/books/pancreatitis-treatmentand-complications/pancreatic-ascites-and-pleuraleffusion

2. Cameron JL. Chronic pancreatic ascites and pancreatic pleural effusions. Gastroenterology 1978 Jan;74(1):134-40.

3. Balasubramanian P, Jeyamani R, Govil S, et al. Pancreatico-pericardial fistula: a rare complication of chronic pancreatitis. Indian J Gastroenterol 2004 Jan-Feb;23(1):31-2.

4. Ching SS, Rao MM, Ali A, et al. Chronic pancreatitis complicated by pancreaticopericardial fistula. Surgical Practice. 2007; 11(3):130-133.

5. Sommer CA, Wilcox CM. Pancreatico-pericardial fistula as a complication of chronic pancreatitis. F100oRes 2014 Jan 29;3:31. 
Access full text article on other devices

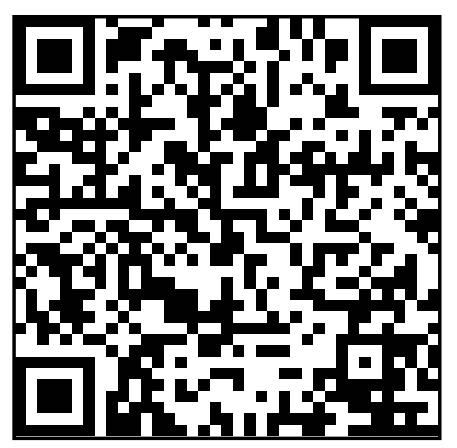

Access PDF of article on other devices

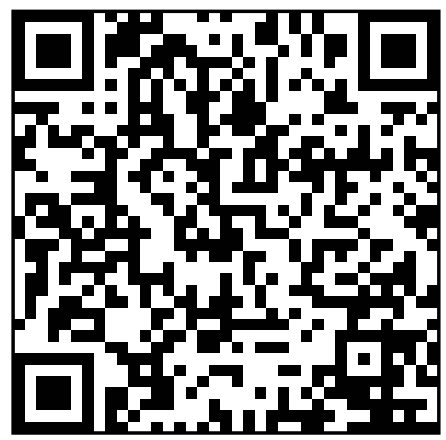

